\title{
Líderes agrarios, identidades anticlericales y acción colectiva en la etapa del Frente Popular
}

\author{
Julio Prada Rodríguez
}

PALABRAS CLAVE: anticlericalismo, acción colectiva, Iglesia católica, Segunda República.

CÓDIGOS JEL: J51, J52, Z12, Z13.

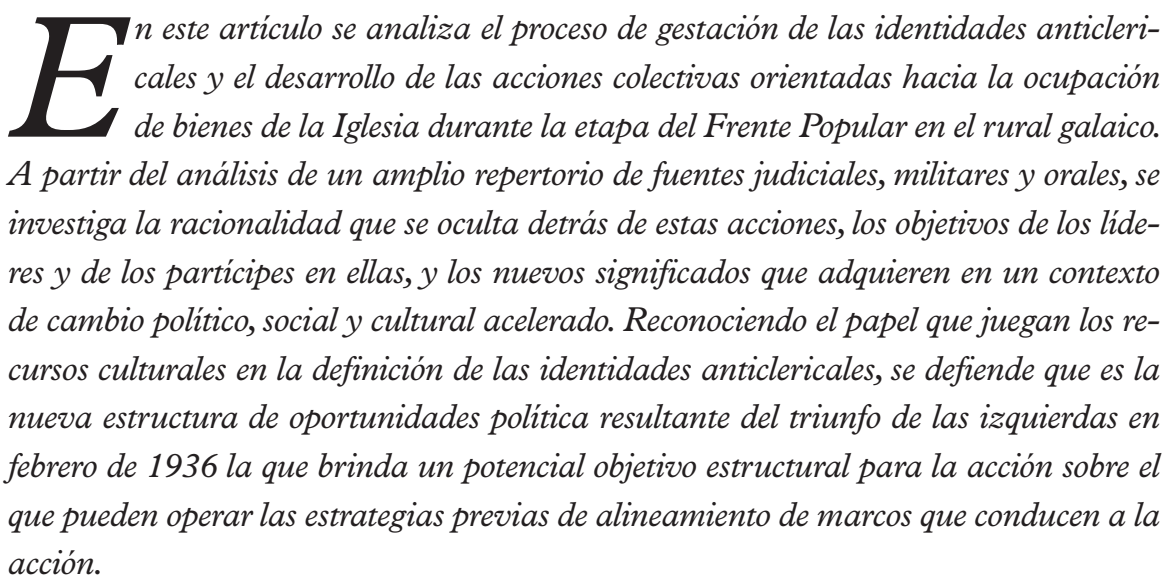




\section{Agrarian leaders, anticlerical identities and collective action in the Popular Front period}

\section{KEYWORDS: anticlericalism, collective action, Catholic Church, Second Republic.}

\section{JEL CODES: J51, J52, Z12, Z13.}

his article analyses the gestation of anticlerical identities and the development
of collective actions to occupy Catholic Church properties during the period
of the Popular Front in rural Galicia. We also look into the rationale behind these actions, the objectives of the leaders and participants and the new meanings these actions acquired in a context of accelerated political, social and cultural change. While recognizing and valuing the importance of cultural resources in defining the anticlerical identities, we defend the essential and activating role of the new political opportunity structure that opened up after the triumph of the Popular Front. 


\section{INTRODUCCIÓN: [...] LAS AGUAS DE 1936 VIENEN CORRIENDO DE BIEN LEJANAS CORDILLERAS}

Largo ha sido el camino recorrido por los estudios sobre el anticlericalismo español desde que A. Montero Moreno (1998) sintetizó con la frase que encabeza este apartado su tesis de que la explosión que se vive tras el inicio de la Guerra Civil representaba el capítulo final de un largo proceso histórico que se habría iniciado en la segunda década del siglo XIX. La polémica en torno a sus orígenes estuvo presente en muchas de las investigaciones pioneras, alguna de las cuales remontaba sus raíces hasta la Edad Media (Caro Baroja, 1980). Sin embargo, se plantease más como el producto de las transformaciones sociales vinculadas a la emergencia de la sociedad industrial (Callahan, 1989) o se destacase su persistencia a lo largo del tiempo hasta configurarse como un elemento cultural de cierta estabilidad (Castro, 1997), lo cierto es que abundaban las interpretaciones simplistas y las reticencias a reconocer que el anticlericalismo poseía una entidad propia y diferenciada que desaconsejaba visualizarlo como una especie de epifenómeno tras el cual se ocultarían realidades más profundas (Pérez Ledesma, 1999).

La cuestión de las «motivaciones» a las que obedecían los protagonistas de las acciones anticlericales fue otro de los elementos centrales del debate. Frente a la extendida idea inicial de que se trataba de comportamientos irracionales e instintivos de las turbas que sólo podían ser calificados de contraproducentes en aras de la consecución de objetivos políticos o sociales, las primeras aproximaciones desde los ámbitos antropológico ${ }^{1}$ e histórico $^{2}$ ya advirtieron, antes de finalizar los años ochenta, de la necesidad de prestar una mayor atención a los aspectos culturales del fenómeno. La década siguiente trajo consigo importantes novedades que llegaron, sobre todo, de la mano de la antropología cultural y supusieron un salto cualitativo en su interpretación al situar en primer plano cuestiones como la simbología, los rituales o los significados de la religión popular y del anticlericalismo ${ }^{3}$, lo que permitió encontrar sentido a tales acciones y a la vez descartar la idea de que estaban presididas por la sinrazón, el instinto, las pasiones o el sinsentido (Cruz, 1997: 220).

Desde entonces, las investigaciones se han multiplicado, aunque resultan desiguales según el aspecto concreto que suscite nuestro interés. Por un lado, se han realizado diversos balances que, al mismo tiempo que sintetizan los avances realizados, sugieren nue-

1. Christian (1978); Gilmore (1980); Lincoln (1981, 1985); GeERTZ (1987); Aston (1988); Mitchell (1988); Delgado (1989).

2. Álvarez Junco (1985); Ranzato (1988); Raguer (1989).

3. Chadwich (1990); Delgado (1993, 1997, 2012); Christian (1997). 
vas líneas de investigación ${ }^{4}$. Por otro, se ha consolidado una inabarcable línea de investigación de larga tradición, a la que genéricamente se suele denominar de la persecución religiosa, cuyos cultivadores muestran gran preocupación por cuantificar el número de víctimas de la furia anticlerical y el volumen de la destrucción del patrimonio eclesiástico reproduciendo, por lo general, viejos esquemas interpretativos sin apenas concesiones a las aportaciones procedentes del ámbito de la antropología, de la psicología social o de la sociología ${ }^{5}$. No faltan, en fin, trabajos que continúan profundizando en líneas anteriores y que tercian en alguna de las principales cuestiones que continúan siendo objeto de debate $^{6}$, incluida la reacción de las autoridades ante la violencia anticlerical ${ }^{7}$ y el intento de poner rostro a los protagonistas de dichas acciones o de subrayar su papel en la creación de identidades colectivas ${ }^{8}$.

En cambio, no abundan los estudios de caso que hagan posible descubrir cuál es la identidad de los protagonistas de las acciones anticlericales, sus motivaciones, los mecanismos que las activan, los marcos de referencia de aquellos y su relación con la explosión societaria que precede al golpe de Estado de julio de 1936. La escasez de fuentes ha sido un obstáculo que contribuye a explicar este vacío, por lo que se hace preciso combinar un variado repertorio de fuentes judiciales militares y civiles, la correspondencia privada de los actores y sus testimonios orales, y la documentación de origen gubernativo para componer un relato que permita responder a dichos interrogantes a nivel micro sustentados por las aportaciones de los teóricos de la acción colectiva.

En este sentido, los progresos en la interpretación de los movimientos sociales como instancias generadoras de marcos de referencia han permitido destacar su fuerza cognitiva para definir el significado de los acontecimientos y de los objetivos hacia los que se orientan (Gusfield, 1994: 105-106). Son ellos los que establecen las conexiones ideológicas entre individuos y grupos y, de forma simultánea, proponen y refuerzan las identidades al posicionar a grupos relevantes en el tiempo y en el espacio, y atribuirles unas características que implican relaciones específicas y líneas de acción comunes. De este modo,

4. Cueva (1997, 1998, 2001); VinCENT (2005); BARRIOS (2007); LEDESMA (2009). Interesantes aportaciones desde el punto de vista comparativo para el caso de Portugal en DUARTE (2014).

5. Al margen de las incontables monografías locales y sin ánimo de exhaustividad, véanse CÁRCEL Ortí (1990, 1995, 1999, 2000, 2008), Montero (1998), MARTín Rubio (1999, 2001, 2007), PONS (2000), Alcalá (2001), Peraire (2001), Jimeno y Jiménez Gómez (2004), Guijarro (2006), GonzÁlez Rodríguez (2007), Martínez Puche (2007), Hernández Figueiredo (2009), Pérez Arnal (2010) y NúÑEZ LÓPEZ (2010).

6. Delgado (2001); Albertí (2008). Una síntesis de estos trabajos en Ledesma (2009: 14 y ss.).

7. Álvarez Tardío y Villa (2013).

8. Thomas (2014). 
en el campo de la acción colectiva se promueven y reafirman unas identidades individuales y colectivas a través de la participación en la acción y mediante los procesos de creación de marcos de referencia que se utilizan para destacar determinados aspectos de la realidad (Hunt, Benford \& Snow, 1994: 221-222). Sin embargo, la diversidad de significados que puede derivarse de diferentes experiencias de los mismos hechos exige no sólo identificar a los protagonistas de una determinada acción colectiva, sino situar los acontecimientos en un marco de referencia, que puede ser muy variable en función de las concepciones e intereses de cada uno de los participantes. Para analizar este complejo proceso en el que interactúan la creación de marcos de referencia y la construcción de las identidades anticlericales en el mundo rural galaico anterior a la Guerra Civil, nos centraremos en la ocupación de diversas propiedades eclesiásticas, sobre todo rectorales, de las que -utilizando la terminología de Hunt, Benford y Snow- disponemos de abundante documentación procedente de los diferentes campos de identidad que intervienen en ella.

\section{LABRANDO EL SURCO...}

Los acontecimientos de octubre de 1934, a pesar del precedente de los numerosos ataques a templos producidos desde el verano de $1931^{9}$, no derivaron en las diócesis gallegas en una explosión de anticlericalismo semejante a la que sacudió Asturias, Cataluña, Burgos o León. Tampoco la entidad del movimiento insurreccional alcanzó las cotas de algunas localidades de las provincias citadas. Aun así, la declaración del estado de guerra fue aprovechada por las autoridades para intentar desmantelar el tejido societario existente, acusando a sus responsables de simpatizar con la causa de los revolucionarios ${ }^{10}$. Anticipando lo que sería norma a partir de julio de 1936, los informes que obraban en los puestos de la Guardia Civil, pero también los de los párrocos, serían decisivos para identificar a los dirigentes más activos, por lo que a la larga la dinámica generada por dichos acontecimientos resultaría esencial en el proceso de alineamiento de marcos que conduciría a la aparición de nuevas manifestaciones anticlericales, que hasta entonces no habían tenido ocasión de manifestarse.

El ritual no debió diferir en exceso de lo acontecido en San Miguel do Outeiro (Vilamartín de Valdeorras), donde radicaba la sociedad de campesinos El Porvenir: la Guar-

9. El Ideal Gallego, 03/07/1931, p. 1. La Región, 17/06/1933, p. 1 y 29/07/1933, p. 1. Archivo Intermedio Militar Noroeste (AIMN), causa 434/1937, fol. 43a; HERNÁNDEZ FIGUEIREDo (2009: 140141).

10. Solo en el caso de Lugo, Souto (1997: 172-175) contabiliza 108 sociedades clausuradas repartidas por 37 municipios. 
dia Civil se presenta en el inmueble que constaba oficialmente como sede, invariablemente una casa particular, se incauta de la escasa documentación existente, registra los domicilios de los «extremistas» más conocidos de la aldea y aprovecha para detener a los más activos con el pretexto, real o ficticio, de estar implicados en la huelga. Fue lo que le ocurrió, por ejemplo, al que pocos años después se convertiría en un destacado líder del PCE, Santiago Álvarez Gómez, y a otros ocho afiliados al Sindicato Campesino de la vecina aldea de Correxais, entre ellos su presidente, Jesús Rodríguez Sánchez, y el que fuera candidato comunista en las legislativas del año anterior, Domingo Mateo Dobao ${ }^{11}$. Lo mismo sucedió con las ocho sociedades adheridas en la comarca a la Federación Nacional de Trabajadores de la Tierra (FNTT), censadas por M. González Probados (1992: 184), y con otras que oficialmente figuraban como no adscritas.

Los párrocos de San Miguel y de San Pedro de Correxais debieron contemplar con satisfacción las detenciones, al menos a juzgar por el hecho de que ambos habían proporcionado detallados informes sobre varios de sus feligreses, no precisamente en términos benevolentes. Y eso a pesar de que hasta entonces no nos consta que en el Ayuntamiento se hubieran producido graves incidentes de naturaleza anticlerical que fueran más allá de algún entierro laico. Las grandes presiones desde las corporaciones locales para que la legislación laicista del primer bienio se aplicase en toda su dimensión no existían en el municipio ${ }^{12}$, donde el «ruido» anticlerical parecía restringido a contados simpatizantes comunistas y a algunos socialistas radicalizados. No obstante, ambos sacerdotes, al igual que sucedía con otros muchos de la diócesis de Astorga, a la que pertenecía Valdeorras, hacía ya tiempo que asistían impotentes a la multiplicación de sociedades y sindicatos que les disputaban con notable éxito el control ideológico de sus antaño mansas ovejas, gracias a sus progresos sobre el control del mercado de trabajo y, sobre todo, al monopolio de la expedición de los carnés sindicales requeridos para trabajar en las siegas en Castilla.

Si dicha impotencia emerge del tenor literal de dichos informes, el deseo de hacer visible la derrota de los izquierdistas en el ámbito simbólico también se percibe claramente en lo ocurrido tras la clausura de sociedades y sindicatos. En todas las iglesias del valle se celebraron solemnes te deum y misas en honor de los muertos de Asturias en los que participaron, hermanados, sacerdotes, miembros de las fuerzas del orden, propietarios de

11. Archivo Histórico Provincial de Ourense (AHPOU), fondo TRRP (Tribunal Regional de Responsabilidades Políticas), caja 7203, exp. 19/1941, fols. 18 y 44; Álvarez (1989); La Voz de Galicia, 14/11/1934, p. 9.

12. El papel de las corporaciones locales en la aplicación de la política laicista en CRUZ (2006: 48) y REY (2008: 168). 
significación derechista como los Sierra, los Macia, los Prada o los Folla, y no pocos medianos labradores que también miraban con recelo el discurso y el modo de proceder de esa porción de sus vecinos que, por necesitar completar sus magros ingresos con el trabajo a jornal fuera de sus fincas, se habían dejado arrastrar por las promesas del «paraíso comunista».Y hasta allí llegaron también los ecos de las cuestaciones en favor de las tropas gallegas que habían acudido a combatir a los rebeldes y las celebraciones públicas en honor a los "héroes» del Principado. Fue entonces cuando Sergio, un joven jornalero de dieciocho años afiliado al Sindicato Campesino de Vilanova (O Barco de Valdeorras), dejó de acudir con puntualidad a la iglesia como venía haciendo desde niño: Escuchar al cura dar gracias a Dios cuando habia tantos que estaban en la cárcel [...] Habia que tragar, y entonces el clero estaba muy comprometido [... $]^{13}$.

Quizá en tan «esplendorosas celebraciones» podamos encontrar parte de las claves del reforzamiento de ese anticlericalismo latente que facilitaría a los apóstoles de la movilización la siempre complicada tarea de la construcción simbólica del nosotros frente al los otros. Pero no menos determinante que esa dimensión simbólica parece haber sido la dimensión política y social de la actuación del clero desde mediado el primer bienio. El impulso que de su mano recibieron las secciones locales de Acción Popular y su proximidad al calvosotelismo están fuera de toda duda, como certifica la correspondencia mantenida con los principales dirigentes provinciales de ambos grupos ${ }^{14}$.Y si dicha implicación no pasó desapercibida a sus parroquianos, mucho más estentóreo resultó su intento de disputar a los propios dirigentes sindicales el control del mercado de trabajo que constituía, como apuntamos, su mejor baza a la hora de atraer adeptos y conciencias. Así hizo, por ejemplo, el ecónomo de Fontei (A Rúa), José Germán Yáñez, que meses antes de los acontecimientos que nos ocupan ya había marcado el camino a seguir por sus hermanos organizando, con un grupito de jóvenes selectos, la Juventud de Acción Católica y más tarde el Sindicato Profesional Obrero, cuyos afiliados pasaron a ser los preferidos de los principales propietarios a la hora de contratar jornaleros ${ }^{15}$.

Sin embargo, la victoria resultó mucho más efímera de lo que aquellos combativos párrocos pudieron imaginar. Bastó que el Gobierno decretase el final del estado de guerra para que la conflictividad sociopolítica recuperara el pulso. Los mítines y manifestacio-

13. Reconstrucción textual de la entrevista mantenida por el autor el 11/08/2000 con vecinos deVilanova de Valdeorras copartícipes y descendientes de participantes en la acción colectiva (original en gallego).

14. Centro Documental de la Memoria Histórica (CDMH), PS Madrid, leg. 1626; AHPOU, fondo Taboada Tundidor, correspondencia s/c; Archivo de la Diputación Provincial de Ourense (ADPO), fondo Pérez Ávila.

15. CDMH, PS Madrid, leg. 1626. 
nes públicas se multiplicaron uniendo a comunistas, socialistas, republicanos de izquierda y nacionalistas gallegos pertenecientes al sector más izquierdista del Partido Galeguista (PG) ${ }^{16}$. Semejante conglomerado apenas tenía otra cosa en común que la bandera de la liquidación de las responsabilidades de octubre, pero todos acreditaban parecido resentimiento hacia los detentadores del poder local y hacia quienes, en estrecha connivencia con estos, continuaban disponiendo de la llave de las almas y las conciencias de la mayoría de sus convecinos. Tampoco faltaron ejemplos de ocupación de propiedades usurpadas por los pequeños notables locales, como la que narra el ya citado $S$. Álvarez con todo lujo de detalles (1985: 108-109).

Esta movilización va acompañada de un intento de consolidar el marco asociativo anterior bajo un nuevo prisma. Ya no se trata de lograr la mera reapertura de las sociedades cerradas por la autoridad gubernativa, sino de fundar otras sobre bases diferentes como ocurre, sin ir más lejos, con El Porvenir, cuyos dirigentes consiguen burlar la orden de clausura fundando una nueva entidad: la Sociedad de Trabajadores de la Tierra deVilamartín, que no sólo absorbe a la práctica totalidad de los antiguos afiliados de San Miguel do Outeiro, sino que extiende sus redes sobre las parroquias próximas a la vez que marca la dirección de los diferentes "comités». Con ello se sientan las bases para superar el minifundismo y la dispersión anterior y, sobre todo, comienza a declinar la influencia que algunos notables tradicionales todavía conservaban sobre las sociedades, a las que habían utilizado al servicio de la tradicional política de bandos que la República todavía no había conseguido desterrar.

Tal vez el mejor indicador del éxito logrado en la forja de un marco identitario nucleado por la conciencia de unos objetivos compartidos sea los resultados de las elecciones de febrero de 1936: en una provincia en la que el Frente Popular no fue capaz de obtener siquiera un acta de las nueve en disputa, en Valdeorras se impuso en cuatro de sus siete ayuntamientos, y el candidato del PCE obtuvo los mejores resultados de toda la circunscripción ${ }^{17}$. No sorprenderá, por ello, que al caer la tarde del día 18 las primeras manifestaciones de júbilo combinasen casi a partes iguales los vivas al Frente Popular y al UHP con los mueras al fascismo, el clero y la reacción, a la vez que se exigía un cambio en la composición de los ayuntamientos (en su mayoría en manos de radicales y cedistas) acorde con la voluntad popular. El gobernador civil interino nombrado por el nuevo gobierno de Azaña, Fructuoso Manrique, designó a las primeras gestoras locales, que ya reproducían los nuevos equilibrios de poder resultantes de los comicios. En Valdeorras la mayoría de las alcaldías fueron para Izquierda Republicana, pero en todos los muni-

16. AIMN, causa $282 / 1939$, fol. 54a.

17. AHPOU, fondo Diputación Provincial, caja 3.070, «Acta de Escrutinio General». 
cipios la presencia de socialistas, comunistas, algunos galleguistas y líderes locales de sociedades y sindicatos era muy relevante. Incluso en Vilamartín la presidencia del Consistorio recayó en un socialista, Augusto Sierra, un labrador acomodado, dirigente del Sindicato de Campesinos e implicado en los sucesos de octubre de 1934; la primera tenencia de alcaldía fue para un comunista, el mencionado Santiago Álvarez, que de forma muy expresiva retrató el significado del cambio en la corporación: Las gentes de los pueblos empezaban a alzar la frente y a tratar de otro modo al cacique, al cura reaccionario, al juez. Tenían menos miedo a la Guardia Civil. «Ahora mandan os nosos», decían (1985: 160).

Este último, al igual que el máximo dirigente provincial del PCE, Benigno Álvarez, consideraba que en aquellos momentos el mejor modo de que el Gobierno cumpliese con celeridad los pactos electorales era tomar la iniciativa desde la base y dar inmediata satisfacción a las reivindicaciones de una parte de sus bases sociales. Siguiendo la estela marcada por el diputado electo por Pontevedra, Adriano Romero Cachinero, ambos coincidían también en que el crecimiento del partido pasaba por mantener la espiral reivindicativa y a la vez hacerse con el control de los sindicatos agrarios existentes, impulsar la creación de otros nuevos y atraer a la mayoría a una gran Federación Provincial que aspiraban a controlar siquiera de modo indirecto. La comarca de Valdeorras había sido la primera en implementar esta estrategia y también donde mejores eran los frutos y las expectativas de futuro.

\section{3. [...] EL GOBIERNO ORDENABA QUETODAS LAS CASAS- RECTORALES ERAN DE LOS PUEBLOS}

Las celebraciones por la victoria se confundieron en toda la comarca con las fiestas de carnaval, preludio de los cambios en las gestoras y de la imponente manifestación que recorrió el valle el domingo 1 de marzo sembrando la inquietud entre los sectores conservadores. $Y$ antes incluso de esta última, el estallido de una ola anticlerical sin precedentes, de la que da fe el informe enviado por el obispo de Astorga al nuncio Federico Tedeschini el día 1 de abril. En apenas mes y medio, doce sacerdotes de la diócesis habían sido obligados a abandonar sus parroquias y otros nueve, a pesar de las amenazas, permanecían firmes en sus puestos. Siete casas rectorales habían sido ocupadas y una saqueada aprovechando la ausencia de su titular; otras dos habían sido apedreadas o recibido disparos, y otros nueve párrocos habían sido amenazados para que entregasen las iglesias, las rectorales o las huertas, pero como se habían negado viven en continuo peligro y sobresalto. Una iglesia había sido incendiada y otra está en poder de los revoltosos, quienes han celebrado en la misma algún mitin o reuniones profanas; otra ha sido robada y saqueada. Además, en varios casos se les había prohibido celebrar cultos o catequesis y en 
otros dos los oficiantes hubieron de suspender la misa por tumulto antirreligioso promovido en el atrio de la iglesia (Hernández Figueiredo, 2009: 247-248).

Nada decía el prelado de quiénes eran los protagonistas de aquellos actos, qué objetivos perseguían y a qué estrategias servían. Pero que los documentos guardasen silencio estaba muy lejos de significar que él o sus subordinados ignorasen lo que estaba sucediendo en una parte significativa de esas parroquias a las que aludía el informe, al menos a juzgar por los detallados testimonios que meses después prestarían en las causas militares incoadas por la jurisdicción de guerra tras el golpe de Estado. Entre ellas la de San Pedro de Correxais, donde el 23 de febrero, domingo de carnaval, los afiliados al sindicato agrario local, encabezados por Benigno Álvarez y Santiago Álvarez, reforzados por otros sindicalistas de la comarca, consumaron la primera incautación de propiedades de la Iglesia en Valdeorras tras las elecciones. Según el alcalde de barrio, el primero de dichos dirigentes

\section{[...] preguntó a los reunidos si habian abierto la Casa Rectoral, contestándole el de- clarante que no; entonces contestó el Benigno Álvarez: «pues ya debía de estar abierta, puesto que el Gobierno ordenaba que todas las Casas-Rectorales eran de los pueblos»; que en este momento el que declara les dijo que ya que estaban ellos allí era el momento de abrirla, penetrando seguidamente en su interior $[\ldots]^{18}$.}

De esta concisa narración, interesa retener un elemento que resulta clave para entender el porqué de la proliferación de actuaciones anticlericales de esta naturaleza por diferentes puntos de la geografía gallega, sobre todo en la diócesis de Astorga, donde eran casi por completo desconocidas. Se trata del discurso empleado por ambos líderes comunistas para justificar la incautación del edificio. En una valoración racional del coste de la acción, quienes tomaron parte en estos hechos deberían esperar una respuesta del Estado en forma de intervención de las fuerzas del orden. Por eso, descontando los móviles concretos y la finalidad última de aquella, se justifica ante los vecinos diciendo que es el propio Gobierno el que dispone que todas las rectorales eran de los pueblos. No debió ser casual que, días después, el Gobierno Civil ordenase a los consistorios del partido publicitar un bando en el que se amenazaba con la destitución a todos los alcaldes que permitiesen ataques a las rectorales, propiedades de religiosos e iglesias, y se advertía que se haría intervenir a la Guardia Civil para reprimir tales desmanes.

Pero tales admoniciones no pasaron del papel. Para entonces, todos los párrocos tenían instrucciones precisas de sus superiores en el sentido de no ofrecer resistencia ac-

18. AIMN, causa 369/1936, fol. $18 v$. 
tiva ante actos semejantes: en primera instancia no cederían, pero si la petición persistía y veían peligrar su integridad, acreditarían documentalmente el atropello y claudicarían. Y así lo hizo el de Correxais: hasta en dos ocasiones se negó a entregar la rectoral a otras tantas comisiones, ofreciendo a la segunda resignar si sus integrantes firmaban un documento en el que constase su entrega al sindicato, pero la directiva ordenó su ocupación por la fuerza sin rubricar escrito alguno para no comprometerse. El sacerdote, obligado a ausentarse, abandonó también las llaves de la iglesia. A continuación, varios dirigentes, encabezados por el presidente Santos López García, penetraron en el templo, sacaron del interior el pendón y el palio, retiraron las imágenes de altares y hornacinas, y trasladaron los bancos a la rectoral toda vez que en Correjanes no habría de volver a celebrarse el culto católico. A continuación, el sastre, Valentín Fernández, transformó divisa y dosel en una artística bandera comunista compaginando las letras del referido pendón [...] para que dijera Sindicato C. P. de Campesinos de Correjanes, haciendo también la hoz y el martillo en la nombrada bandera con género negro ${ }^{19}$.

Culminaba, de este modo, la politización del espacio sacro reclamada por los protagonistas de las acciones anticlericales. De igual modo que con la secularización, las comunidades locales se veían desposeídas por la violencia del dominio espacial que ejercían a través de la territorialización sacramental y en su lugar aparecía el Estado como único ente de organización y fiscalización del paisaje (Delgado, 1997: 180); ahora el espacio sagrado se socializaba y se llenaba de nuevos contenidos simbólicos asociados a la desterritorialización de lo sacro, la humanización de las imágenes y, sobre todo, la sustitución de la mística religiosa por la mística de lo político ${ }^{20}$. Así tendría ocasión de comprobarse menos de un mes más tarde en la aldea de Vilanova (O Barco $)^{21}$. Como en el caso anterior, el campo de los protagonistas estaba perfectamente delimitado: sus organizadores fueron también elementos vinculados al sindicato campesino local, la mayoría militantes comunistas y socialistas, e incluso alguno de procedencia libertaria. En la ocupación, quizá todavía más tumultuaria y ritualizada que en el caso de Correxais, participaron gran parte de los vecinos de la aldea, incluidos, como solía acontecer, numerosas mujeres y niños. El campo de los antagonistas activos estaba personificado en el párroco, Magín Nogueira Martínez, y en sus apoyos en la parroquia, todos ellos muy implicados en las luchas de poder local y en el apoyo a las candidaturas de la CEDA y el Bloque Nacional. El de las

19. Las citas anteriores en AIMN, causa 369/1936, fol. 18v.

20. Sobre el carácter laicista o anticlerical de este proceso, véanse LóPEZ VilLAVERDE (2008) y MORAL (2012).

21. Véanse las notas 22 a 25 para lo relativo a las fuentes en las que se basa la argumentación relativa a la politización del espacio sacro, la configuración de los distintos campos y la elaboración de los marcos de diagnóstico, pronóstico y motivación. 
audiencias traspasó los estrechos límites del Ayuntamiento, como enseguida tendremos ocasión de comprobar.

El proceso que condujo a la movilización se inició con la elaboración de un marco de diagnóstico, mediante el cual los dirigentes identificaron y realzaron una situación problemática, singularizando y personificando a los que se consideraban sus responsables. Como han demostrado los estudiosos de la acción colectiva, esto se realiza a través de la atribución de unos roles que objetivamente pueden resultar ficticios o reales, pero que deben ser percibidos como ciertos e indudables para los integrantes del campo de los protagonistas, en la línea de lo propuesto por K. Dieter Opp (2009). En la ocupación de la rectoral de Vilanova intervinieron una gran cantidad de elementos en el diagnóstico, habida cuenta de que la situación conflictiva no era ni mucho menos patrimonio exclusivo de esta parroquia, sino que se inserta en un marco mucho más amplio que podemos sintetizar remitiendo a lo que era la interpretación clásica de las izquierdas marxistas en lo tocante a la descripción de la explotación de la clase trabajadora y a la culpabilización de tal estado de cosas. Ahora bien, esta caracterización genérica, sobre la que podemos admitir que existía un cierto consenso inicial fruto de un trabajo de concienciación anterior, que hemos ido esbozando en las páginas precedentes, resulta insuficiente para provocar la movilización. Es necesario territorializar y personificar la situación de explotación; es decir, identificar en un ámbito espacial definido a las víctimas concretas de la explotación y a su culpable.

Por eso, los límites del perímetro territorial no pueden ser otros que los de la parroquia, el espacio en el que se materializan los actores principales del drama. Por un lado, las «víctimas»; o, para ser más exactos, quienes se van a presentar como víctimas: los jornaleros sin tierra suficiente para garantizar su reproducción familiar y a los que la falta de trabajo coloca en una situación angustiosa. Por otro, los considerados «responsables» de esta situación: en primer lugar, ciertos propietarios que prefieren dejar sin cultivar algunas parcelas antes que transigir con las demandas salariales y de jornada del sindicato local, pero a los que no resulta fácil doblegar rodeados de guardas jurados a sueldo y protegidos por la Guardia Civil; y en segundo lugar, una Iglesia, personificada en el párroco, que aprovecha su condición de «propietaria» para especular con la necesidad de las familias designando entre sus incondicionales a los beneficiarios de los arriendos, pero que, a diferencia de los anteriores, se halla prácticamente inerme ante la inhibición de las autoridades gubernativas y municipales.

Una vez alcanzado el consenso sobre los elementos «objetivos» que justifican la acción es preciso construir un marco de pronóstico, esto es, diseñar una estrategia que permita corregir la situación percibida como injusta. En esta definición de objetivos, tácticas, ac- 
tores y, en definitiva, recursos susceptibles de ser movilizados, entra en juego toda una serie de factores relacionados con la estructura de oportunidades políticas en la que operan, en particular, la valoración de la ecuación coste previsible/beneficio esperado de la acción. Como no podía ser de otro modo, los dirigentes sindicales de Vilanova tuvieron muy presente lo ocurrido en Correxais tras la completa inhibición de la fuerza pública durante los veintiocho días que precedieron a esta nueva ocupación. El hecho de que en este y en otros casos similares no se produjese ninguna reacción dejaba abierta la posibilidad de imaginar un pronóstico exitoso, incluso si se intentaba avanzar un paso más allá de lo acontecido en otras aldeas.

Durante esta fase se hace necesario establecer, por fin, unos marcos de motivación, que son los que impulsan de forma directa la acción colectiva mediante un proceso de construcción social y de reconocimiento de las justificaciones e identidades compartidas de los protagonistas. En este caso el proceso está estrechamente relacionado con los dos niveles esbozados con anterioridad: el discurso empleado reitera elementos ya utilizados durante la creación de los marcos de diagnóstico y de pronóstico, con la matización de que ahora se dirige a fomentar el alineamiento de las identidades individuales y las construcciones explicativas de los individuos con las identidades corporativas y la lectura realizada por los organizadores de la acción, procurando así la conciliación de las expectativas de unos y otros. En este punto los sistemas de creencias desempeñan un rol esencial, ya que este tipo de acciones, en especial en los niveles de planificación, sólo se pueden llevar a cabo si las diferencias ideológicas y las identidades no resultan irreductibles o antagónicas y existe, por tanto, la posibilidad de hacer congruentes sus respectivas cosmovisiones. Como relataba uno de los vecinos,

[...] era cosa de todos, de toda la parroquia [...] Los que eran de ideas más avanzadas pues decian que habia que acabar con aquella explotación, que el comunismo era la redención de todos nosotros, de todo el mundo. $Y$ es verdad que muchos pensaron que con apropiarse de las tierras de los ricos ya se arreglaba todo, que ya no habría miseria ${ }^{22}$.

Mediante la participación en los diferentes actos de preparación y ejecución del complejo de actividades funcionalmente racionalizadas que conducen a la acción colectiva, cada individuo integra de forma gradual su propia interpretación de los acontecimientos en la que realiza el conjunto de los participantes, lo que favorece su socialización. Las relaciones de vecindad jugaban un papel esencial en la definición del campo de identidad de los protagonistas y, por tanto, en las estrategias de alineamiento. Pero, como en

22. Trascripción de la entrevista de fecha 11/08/2000. Véase nota 13.

Historia Agraria, 78 • Agosto 2019 • pp. I6I-189 
Correxais, también lo hacía la casi diaria convivencia en el seno del Sindicato Campesino de los dirigentes y, de forma más esporádica, del resto de los afiliados en un momento en el que la sindicación era práctica obligada para encontrar trabajo.Y tampoco cabe duda que en este caso se aprovecha la experiencia de quienes les precedieron: en aquella parroquia los dirigentes locales del Sindicato Campesino carecían de un referente previo para garantizar el éxito de la fase final de la acción y, por eso, habían acudido a dos avezados propagandistas ya acostumbrados a similares experiencias; ahora, el surco estaba labrado y era suficiente con una eficaz combinación de métodos tradicionales y modernas concepciones de la acción colectiva desarrolladas endógenamente para conseguir que fuese secundada por el mayor número de vecinos.

El domingo 22 de marzo, varios dirigentes del sindicato conminaron violentamente al párroco para que abandonase de inmediato la rectoral y sus fincas ${ }^{23}$. A primeras horas de la mañana del día siguiente, el alcalde del barrio convocó una asamblea vecinal en la que propuso que, a repique de campanas, concurriesen todos para tomar posesión de ellas. Aunque, según el sacerdote, gran parte de los presentes rechazó la invitación, otros, en número de 30 a 40, estimulados por la codicia, prometieron concurrir, y decidieron enviar como avanzadilla a varios niños. Y así,
[...] de 8 a 9 de la mañana penetraron ya en la huerta y prado más próximos a la rectoral multitud de chiquillos con ganado vacuno, recorriendo toda la huerta y encaramándose por los árboles de la misma como legítimos dueños, oyéndose de vez en cuando de boca de aquellas criaturas las palabras jviva el comunismo li-

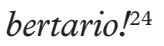

Del relato del párroco se desprende con claridad cómo, además de la ocupación física, los participantes en la acción tenían un marcado interés en subrayar la apropiación simbólica y la secularización de un espacio en la línea ya apuntada páginas atrás:

Llegó la turba de 1 a 2 de la tarde, penetró en la casa violentamente, recorrió sus habitaciones, señaló con letreros las que dedicaban para casa del pueblo y casa-habitación y local para ambas escuelas del pueblo, todo esto a toque de campanas, música y fuegos artificiales, continuando la broma hasta altas horas de la noche. Izaron también la bandera nacional en uno de los balcones de la cas $a^{25}$.

23. Archivo de la Audiencia Provincial de Ourense (AAPO), libro de sentencias de 1938, sentencia 54/1938, fol. s/n.

24. Manuscrito del párroco Magín Nogueira en CDMH, PS Madrid, $1626^{2}$.

25. CDMH, PS Madrid, $1626^{2}$. El fiscal, sin embargo, señala que en la parte exterior de un balcón 
A pesar del «estatismo» con el que solemos retratarlas los historiadores, las acciones colectivas son esencialmente dinámicas. Esto quiere decir que durante las diferentes fases que median entre su preparación y finalización tienen lugar un conjunto de tensiones y negociaciones múltiples en las que intervienen elementos pertenecientes a los tres campos de identidad de los que hablábamos. Hasta este instante, la iniciativa había correspondido a los protagonistas, pero dos días después de consumarse la ocupación entrarán en juego nuevos elementos que estuvieron a punto de provocar una redefinición de los objetivos inicialmente propuestos. En Vilamartín, como apuntamos, el Ayuntamiento, incluida la presidencia de la comisión gestora, estaba controlado por socialistas y comunistas, que desoyen las quejas formuladas por el párroco. En O Barco, por el contrario, la mayoría la ostentaban hombres vinculados a IR y al PG, muy alejados, incluso desde el punto de vista de la extracción sociológica, del maximalismo de aquellos, pero muy condicionados por su peso en los comités locales del Frente Popular. Por eso, nada tiene de extraño que el alcalde de esta última localidad acepte la mediación propuesta por el sacerdote e imponga un principio de acuerdo según el cual el pueblo respetaría la propiedad de todo lo incautado siempre que los arriendos de las fincas beneficiasen a varias familias de escasos recursos. Tal avenencia permitiría dar satisfacción al elemento esencial que en última instancia había justificado la acción y a la vez consolidaba el papel de los dirigentes frente a la situación de impasse a la que se había llegado y al germinar de las primeras disensiones protagonizadas por quienes consideraban que se habia llegado demasiado lejos.

Como bien intuía el sacerdote, al someter esta propuesta a votación el conflicto entraba en una fase diferente durante la cual se genera un nuevo marco de redefinición de tácticas y objetivos, y se incorpora al núcleo de los elementos más destacados a nuevos activistas, como prueba el hecho de que la nueva comisión negociadora se ampliara a siete vecinos. Las negociaciones se rompieron cuando el cura se negó a aceptar que respetando la propiedad del párroco y por tanto el derecho a percibir las rentas [...] los arrendatarios fuesen designados por el mismo [pueblo de una lista de treinta y cinco] aun a costa de quedar el párroco para su uso una pequeña parcela. La negativa supuso el inmediato refuerzo de la identidad colectiva de los participantes, ahondando la distinción entre nosotros (abiertos a una negociación y dispuestos a aceptar diferentes alternativas) y ellos (que pretenden perpetuar la situación de miseria y explotación negándose a que sean todos los vecinos quienes elijan a los beneficiarios de los arriendos), lo que les permite presentarse como víctimas de una injusticia. Una estrategia que, además, parecía encaminada a forzar la implicación del mayor número posible de aldeanos en la acción en curso para evitar la pro-

de la casa rectoral se colocó una bandera roja y no la republicana (AAPO, sumario n. ${ }^{\circ}$ 24/1936, fol. $\mathrm{s} / \mathrm{n})$. 
liferación de posibles free riders que intentasen beneficiarse de ella sin asumir su parte alícuota del coste previsible. Resulta evidente la intencionalidad política de esta autorrepresentación de la «injusticia» en la medida en que los arrendatarios actuales formaban parte de esas clientelas dispuestas a secundar los intereses de los sectores a los que representaba el párroco con notable éxito, como ya había podido comprobarse en las elecciones, donde el Frente Popular apenas superó la tercera parte de los sufragios (el tercer peor resultado de todas las secciones computadas del Ayuntamiento) frente a los candidatos conservadores y de centro apoyados por Magín Nogueira ${ }^{26}$.

A partir de este instante, la existencia de un problema social definido por circunstancias objetivas e identificables (la situación de las familias de menos recursos afectadas por el paro) alrededor del que se habían configurado los diferentes framings, comenzó a perder peso en favor de otros elementos a la hora de reconfigurar las estrategias de los distintos sectores implicados.Y lo hizo al mismo tiempo que la participación en la acción posibilitó un aumento en el nivel de concienciación y de consenso de los que tomaron parte en ella, en la dirección apuntada por Klandermans (1994: 204). En efecto, como suele suceder cuando la represión no es percibida en unos términos que hacen inasumible el costo de mantener la acción, la tibia intervención de las autoridades acaba por acercar aún más la identificación entre las identidades en conflicto y provocar una nueva y definitiva redefinición de objetivos que va más allá de los inicialmente propuestos: aunque el alcalde de O Barco puso en conocimiento del gobernador civil los hechos, este se negó a tomar ninguna medida efectiva; y tampoco obtuvieron respuesta alguna los dos telegramas que el sacerdote cursó al presidente del Consejo de Ministros y al ministro de Gobernación solicitando su intervención. El 28 de marzo, Magín Nogueira denunció los hechos ante el Juzgado, pero su titular no pudo hacer efectiva ninguna detención, pues tan pronto como los vecinos se apercibieron de su presencia, tocaron las campanas a rebato y se presentaron en confuso tropel ante el fuez [...] [al que] dirigieron insultos. Días después,

\section{[...] llegaron al Barco unos 30 números de la Guardia Civil,y con algunos de ellos} pudo detener y traer a la cárcel a los 4 procesados, dos de los cuales eran el alcalde de Barrio deVillanueva y un concejal del Ayuntamiento. Al darse cuenta de estas detenciones los otros compañeros revolucionarios recorrieron los pueblos limitrofes para que aquellos compañeros y otros simpatizantes concurriesen al Barco al dia siguiente que era o se celebraba el $5^{\circ}$ aniversario de la República, en nutrida manifestación, y allí, además de celebrar dicho aniversario, pedirían la libertad de los 4 presos de Villanueva, la que exigían a toda costa aun de la vida de los pacíficos habitantes del Barco. En vista de este peligro el fuez de Instrucción, después de un

26. AHPOU, fondo Diputación Provincial, caja 3.070, «Acta de Escrutinio General». 
rapidísimo viaje a Orense, puso en libertad a los presos la misma noche del día en que fueron detenidos, vispera del citado aniversario ${ }^{27}$.

De hecho, el Juzgado se vio imposibilitado para continuar con la práctica de diligencias por la oposición vecinal, y no sería hasta mayo de 1937 cuando el fiscal de la Audiencia Provincial ordenó la reanudación de las actuaciones, ampliándose a cuarenta y tres hombres y diez mujeres el número de procesados por aquellos hechos. Gerardo Rodríguez Fernández, el concejal al que se refería el párroco, certificaba el triunfo del vecindario al asegurar que

[...] después de haber asaltado la casa y fincas del Sr. Cura e intervenido el fuzgado el entonces Alcalde, Eulogio Gavela, fue un día a Villanueva y en un mitin que les dio [sic] les dijo que aunque lo que habian hecho estaba fuera de la ley le parecía magnifico; que más tarde recorrió con todo el pueblo las fincas y aprobó la conducta de los vecinos ${ }^{28}$.

Sin duda, ante la incapacidad de los poderes públicos para atender las demandas de sindicatos, sociedades y comités locales del Frente Popular con la celeridad exigida, era mucho más sencillo "legitimar» a posteriori las acciones colectivas que partían de la base y se dirigían contra el más inerme de los enemigos tradicionales. Las turbas, en palabras del párroco, se habían impuesto y habían conseguido doblegar al poder espiritual, al gubernativo y hasta al judicial.

\section{4. ¿TURBAS ANTICLERICALES?}

«Muchedumbre de gente confusa y desordenada». Así es como define el diccionario de la RAE, en su segunda acepción, la palabra turba, expresión que, desde luego, resulta en absoluto impropia para caracterizar a los participantes en las acciones colectivas que acabamos de describir. Quizá nuestro párroco nunca hubiese leído a Burke o Le Bon, pero, en sus descripciones, las «multitudes» que invadieron las tierras a su cargo o recorrieron los caminos del valle a lo largo de aquella primavera se le antojaban masa informe compuesta por desarraigados a los que sólo parecía orientar el deseo de pillaje y que actuaban movidos por móviles irracionales, una visión a la que en absoluto ha sido inmune la historiografía tradicional (Delgado, 2012: 47-48). En cambio, aunque tampoco tenemos constancia de que Santiago Álvarez hubiese hojeado a Michelet, el retrato que de aque-

27. Manuscrito del párroco Magín Nogueira en CDMH, PS Madrid, $1626^{2}$.

28. AAPO, sumario n. ${ }^{\circ} 24 / 1936$, fol. s/n. 
llos episodios realiza en sus memorias bien pudiera asimilarse a aquella visión sublime de las multitudes como encarnación de los ideales puros del pueblo que perfiló el historiador francés. Fue otro historiador británico de origen noruego, George Rudé (2009), quien nos enseñó que la naturaleza de las perturbaciones sociales está íntimamente ligada a la extracción de quienes toman parte en ellas y que esas «multitudes» que desfilan a lo largo de la Historia distan mucho de las dos perspectivas antagónicas que ofrecen uno y otro. Frente a estas, defendió que era preciso elaborar una visión más realista de sus integrantes, de las razones que les impulsan y de los objetivos que persiguen, devolviéndoles, en definitiva, su identidad histórica.

Algo hemos avanzado ya en la dirección propuesta por Rudé. Pero el rostro de nuestras multitudes está todavía lejos de haber quedado por completo perfilado. Para que así sea, necesitamos desprendernos de un primer impulso que bien pudiera ofrecer una imagen no del todo ajustada a lo que aquí nos proponemos: hemos identificado a 704 hombres y mujeres que participaron en diferentes actos anticlericales en la provincia de $\mathrm{Ou}-$ rense entre el 16 de febrero y la declaración del estado de guerra. Pero no diferenciar, por ejemplo, entre quienes queman un templo, agreden a un sacerdote, destruyen cruceiros o imágenes, o toman parte en la incautación de bienes de la Iglesia nos llevaría a conclusiones sesgadas sobre la identidad de los protagonistas debido a que no siempre existe coincidencia de actores ni de motivaciones. En esta aportación hemos optado por limitarnos a estos últimos, a los que fueron acusados de apropiarse de tierras, casas o templos durante el período indicado con independencia de la naturaleza de las motivaciones que los impulsaban.

Las fuentes, comenzando por las vaticanas, están muy lejos de retratar a la totalidad de los partícipes, sobre todo teniendo en cuenta que un porcentaje significativo de estas acciones no llegaron a tomar estado procesal. En unos casos porque no fueron siquiera puestas en conocimiento de los juzgados por los sacerdotes, y tampoco la férrea censura de prensa permitía a los periódicos dar cuenta de ellas. En otros, porque tras la declaración del estado de guerra buena parte de los dirigentes que habían tomado parte en ellas fueron ejecutados, encarcelados o tuvieron que huir como consecuencia de la represión desatada. Aun con estas limitaciones, hemos podido identificar a 424 personas a las que se responsabilizó de haber participado en dichas incautaciones, que en su conjunto suponen nada menos que el $60,23 \%$ del total de participantes en todos los actos de naturaleza anticlerical ocurridos en la provincia durante los cinco meses que preceden a la sublevación militar. Un porcentaje que se explica porque, como hemos podido ver en el relato de los ejemplos seleccionados, el número de los presentes en este tipo de acciones suele ser muy elevado en contraste con los incendiarios o los que provocan daños en los templos, que suelen ser grupos reducidos, al igual que los que amenazan o atacan a sacerdotes. 
De ellas sólo 38 son mujeres, el 8,96\% del total, un porcentaje reducido, pero suficientemente expresivo para concluir que, ni todas ellas estaban sometidas al control ideológico de los curas, ni, a pesar de que la totalidad de estas acciones tienen lugar en ámbitos rurales, permanecían recluidas en sus hogares ausentes de toda actividad pública. Más bien ocurre al revés: esta modalidad de acción colectiva, a diferencia de lo que ocurre con los incendios de templos o los ataques a sacerdotes, en los que suele buscarse la preservación del anonimato, les ofrecía una oportunidad de «hacerse visibles», de diferenciarse en medio de un colectivo integrado en lo esencial por hombres y a la vez hacer patente ante ellos que eran capaces de romper con las pautas tradicionales del «comportamiento femenino adecuado» marcadas por la Iglesia.

En cuanto a la estructura por edades, no se observan grandes diferencias por sexo. Apenas el 2,11\% de los partícipes cuya edad nos resulta conocida (el $89,37 \%$ del total) tenía menos de 18 años, aunque parece evidente que este segmento se encuentra claramente infrarrepresentado debido a la naturaleza de las fuentes empleadas en la investigación (las denuncias suelen omitir, aunque no siempre, a los menores de edad penal). Los jóvenes de entre 18 y 30 años representan el $45,12 \%$ de los conocidos, seguidos a casi diez puntos por los comprendidos entre 31 y 45 años (el 36,41\% del total). Los restantes grupos de edad suponen un porcentaje mucho más reducido: el 12,93\% de los comprendidos entre los 46 y los 65 años y el 3,53\% de los mayores de 65 años. Nada que sorprenda si se tiene en cuenta la intensa politización de los jóvenes durante la Segunda República y la coherencia que manifiestan estas cifras con el conjunto de los represaliados por su actividad política o social durante esta etapa o por su participación en la resistencia al golpe en la provincia (Prada, 2006: 219).

La extracción socioprofesional permite desterrar la imagen de «turba» compuesta por desarraigados rendidos a su afán de pillaje que les atribuía el párroco de Vilanova. Las diferencias de género son en lo fundamental producto de la autodefinición como amas de casa que se atribuye el $41,18 \%$ de las mujeres cuya profesión nos resulta conocida, pues, como es bien sabido, en el rural gallego estas mujeres comparten con los varones las tareas agrícolas y ganaderas además de ocuparse de las faenas del hogar. En su conjunto, conocemos la profesión manifestada por el $89,15 \%$ de los partícipes, tanto hombres como mujeres. El 55,67\% se definían como labradores y una quinta parte (20,63\%) lo hacían como jornaleros, lo que permite colegir -al margen de la exactitud de los porcentajes y de la precisión de las declaraciones- el predominio de los campesinos que poseen tierras en propiedad suficientes para garantizar su reproducción familiar sin necesidad de acudir al jornal, aunque es probable que algunos también completaran sus ingresos con otro tipo de actividades sin hacerlo constar de forma explícita. Unos guarismos que invitan a reflexionar sobre la mecánica atribución al campesinado minifundista gallego de una ideo- 
logía católica y conservadora sin reparar en el hecho de que las particularidades locales, las dinámicas internas de cada comunidad y la transversalidad de identidades enfrentadas dibujan una realidad mucho más compleja y llena de matices que casa difícilmente con la asignación automática de roles, creencias y comportamientos en función de la adscripción a un grupo social determinado.

A mucha mayor distancia, en consonancia con el ya apuntado marcado carácter rural de los espacios donde tienen lugar este tipo de acciones, se sitúan un variado conjunto de profesiones con el común denominador de ejercer su oficio por cuenta propia (sastres, carpinteros, vendedores ambulantes...) y los empleados del sector terciario (3,97\% cada uno), seguidos por el $3,70 \%$ de las amas de casa y el $3,44 \%$ de los estudiantes y menores de edad. Los funcionarios y maestros representan el $2,91 \%$ del total, once casos que a pesar de su reducida participación en el total superan en porcentaje lo que estos grupos aportaban al conjunto de la estructura socioprofesional de las aldeas gallegas. Otro tanto habría que decir de ese $2,12 \%$ de empleados del sector secundario y mineros, quienes en su gran mayoría estaban domiciliados en la comarca de Valdeorras, donde el sector minero gozaba de relativa importancia. Cifras todavía más reducidas suponen los pequeños comerciantes e industriales (que incluyen desde panaderos a propietarios de tabernas, en total un 1,06\%) o los dos casos $(0,53 \%)$ de quienes se definen como propietarios.

Como vemos, una procedencia muy alejada de esa idea de desharrapados o desclasados propensos a vivir en los márgenes de la ley antaño tan en boga. Algo en lo que también incide el hecho de que sólo siete (el 1,81\%), todos ellos hombres, de las 424 personas identificadas tenían antecedentes penales previos, y sólo uno por delitos comunes, stricto sensu: cinco por tenencia ilícita de armas, uno por insulto a fuerza pública y uno por hurto.Y por si guardamos alguna prevención con respecto a la condición social de los participantes, retomemos por un instante lo ocurrido en Vilanova después de que la presión de los vecinos obligase a la puesta en libertad de los detenidos. Semejante claudicación fue determinante para que los dirigentes modificasen el acuerdo de pactar la instalación en las tierras como arrendatarios de los vecinos más desfavorecidos y optasen por proceder directamente a su reparto. Nada mejor que un elemento perteneciente al campo de las audiencias para referir lo acontecido a partir de entonces. Se trata de un vecino de San Lourenzo de Arcos (Vilamartín de Valdeorras), que en una misiva dirigida a Demetrio Macía Valcárcel, el mayor contribuyente por rústica del Ayuntamiento, exmaurista, exdirigente upetista y uno de los hombres fuertes de Calvo Sotelo en el partido judicial, lo relataba en los siguientes términos:

[Las fincas] fueron parceladas, distribuidas y sembradas por unos cuantos vecinos, varios de los cuales -más de tres-, cogen más de 500 cántaros de vino. Vecinos «po- 
bres» no han podido participar en el reparto de bienes, pues estos lo fueron entre gentes que, en su mayor parte, son considerados «ricos» en el pueblo. En cuanto a la Casa Rectoral, su llave fue entregada en el Fuzgado, y por éste al Sr. Cura, pero el soviet sigue disponiendo de ella totalmente; celebran alli sus reuniones, de dia y de noche, y el domingo 10 del actual tuvieron en dich a casa un mitin o conferencia, con intervención del maestro nacional del pueblo, que disertó sobre las excelencias del amor libre, aconsejando la «incautación» de todas las muchachas jóvenes, etc y terminó diciendo que nadie podría echarlos de la casa ni de las fincas, que si el Sr. Cura volvía al pueblo sacarian todas las imágenes de la Iglesia y harían una hoguera con ellas, y que espera para dentro de muy poco que el pueblo deVillanueva sería el primero de España en proclamar el comunismo ${ }^{29}$.

Resulta muy interesante esa referencia a la participación de los ricos en el reparto y a la exclusión de los pobres. Los testimonios orales antes citados y los escasos expedientes de contribución rústica y pecuaria que hemos podido consultar también nos confirmaron que labriegos con tierras propias suficientes para garantizar su reproducción social sin necesidad de acudir al trabajo a jornal o al arriendo se beneficiaron de la incautación, aunque los primeros insisten en que se llevó a cabo en favor de los más necesitados. La propia Jefatura local de Falange, en un informe fechado trece meses después de ocurridos los hechos, certificaba que uno de los que se apropió de una parcela, secretario de la tan repetida Sociedad, pertenecía a la familia más acomodada del pueblo ${ }^{30}$.

Aun situándonos en un punto equidistante de ambos extremos interpretativos de la acción, habremos de concluir que la participación de «toda la parroquia» no fue tan desinteresada como pudiese parecer. Sin duda muchos pudieron actuar movidos por solidaridad con los desfavorecidos, pero la participación de algunos pequeños propietarios finalmente beneficiados se explica por la percepción de la existencia de una oportunidad de mejorar su posición relativa accediendo a una parcela a costa de arrendatarios sin tierras suficientes, pues lo incautado no cubría ni de lejos las necesidades de las 35 familias que figuraban en la lista manejada por el Sindicato. Eso sin contar a los arrendatarios fieles al párroco, que fueron las víctimas propiciatorias de la acción, con lo que se confirma lo ya apuntado con respecto a que no se trataba tanto de garantizar un reparto entre todos los necesitados, sino entre nuestros necesitados; exactamente esos a quienes los líderes debían estar en condiciones de «retribuir», de proporcionar recompensas divisibles o bienes posicionales si querían conservar y ampliar su predicamento y mantener la activación de la protesta.

29. CDMH, PS Madrid, 1626.

30. AIMN, causa 331/1937, fol. 46a. 
La procedencia ideológica de los participantes también contradice la imagen de una «masa» movida por impulsos irracionales. Conocemos la afiliación política de 92 de los 424 participantes en el tipo de acciones que nos ocupan, lo que supone un nada despreciable $21,70 \%$ de afiliación; la totalidad son varones. De ellos, un escaso 3,26\% fueron identificados como cenetistas, faistas o anarquistas, lo cual resulta coherente con la reducida presencia organizativa de estos en las zonas donde se registran ocupaciones de bienes de la Iglesia durante la etapa del Frente Popular y que contrasta, por ejemplo, con su protagonismo en ciudades como A Coruña. Los afiliados al PSOE, las Juventudes Socialistas o las Juventudes Socialistas Unificadas suponen el 41,30\% de los militantes con filiación conocida, seguidos de cerca por los miembros del PCE $(38,04 \%)$. A mucha mayor distancia se encuentran los trece afiliados a partidos de la «izquierda burguesa», doce de ellos pertenecientes a IR y sólo uno a UR (en total el 14,13\%); a ellos habría que sumar otros tres afiliados al PG $(3,26 \%)$.

Los porcentajes de afiliación a sociedades y sindicatos de variada índole resultan todavía más elevados: nada menos que 287 de los 386 hombres identificados (74,35\%) pertenecían a alguna de estas entidades, sin que tampoco tengamos constancia de ninguna mujer afiliada. Los miembros de sindicatos integrados en la CNT suponen el 1,74\% de los conocidos, mientras que el $6,27 \%$ de los que pertenecían a sociedades y sindicatos afines al PCE sólo sorprende por su reducida cuantía en relación al peso de los afiliados comunistas si no se tiene en cuenta que, en un buen número de parroquias y ayuntamientos, estos últimos, aun siendo mayoría, optaron por permanecer en sociedades adscritas a la FNTT por las mayores facilidades de reconocimiento que el carné sindical expedido por esta última encontraba allende sus límites geográficos de origen. Esto explica que los adscritos a sociedades afines a esta última representen el $49,83 \%$ del total de identificados. Otro $12,20 \%$ corresponde a afiliados a sociedades y sindicatos de adscripción múltiple (una parte del sindicato estaba adherido a la CNT y otra parte a la FNTT o incluso a la CGTU antes de que nos conste su integración efectiva en el sindicato socialista) y un $29,92 \%$ a afiliados a sociedades y sindicatos locales cuya adscripción a una central mayoritaria nos resulta desconocida.

El peso que los dirigentes societarios tenían en el conjunto de los partícipes en esta modalidad de acción colectiva también resulta incuestionable: al menos 32 directivos estuvieron implicados, casi siempre ocupando un papel dirigente. Un amplio espectro político y societario representado que constituye la prueba más evidente de hasta qué punto la identidad o identidades anticlericales recorrían de modo transversal las diferentes ideologías republicano-burguesas y obreras, y a la vez representaban una línea de fractura -una más de entre otras muchas- que dividía a la sociedad española antes de julio de 1936. En definitiva, la demostración del alcance de una subcultura política ampliamente compartida 
que era capaz de emerger de forma mucho más nítida que otras categorías más diáfanas sólo en apariencia, como ocurría con la de fascista, y, por consiguiente, de actuar como argamasa de ese conglomerado que convergió en los comités locales del Frente Popular.

Una pincelada final contribuye a perfilar de modo definitivo el rostro de nuestros participantes en ocupaciones de propiedades de la Iglesia durante la etapa del Frente Popular. La primera exige destacar el importante peso de los emigrantes, tanto de larga duración como estacionales: como mínimo 18 hombres eran retornados americanos, un segmento social muy ligado a la movilización sociopolítica en el rural galaico desde finales de los años diez y, en particular, durante la experiencia republicana; otros 16 habían estado emigrados en otras provincias españolas, donde había tomado contacto con sindicatos o sociedades de diversa índole; otros 23 tenían experiencia previa como emigrantes estacionales, la mayoría de ellos a las siegas a Castilla, pero también a la vendimia o como vendedores ambulantes. En total, nada menos que el 14,77\% de los hombres había tenido algún contacto con cualquiera de estas formas de emigración.

\section{CONCLUSIÓN}

Como hemos tenido ocasión de demostrar, las manifestaciones anticlericales analizadas no son simples explosiones de furia irracional, sino que en su gestación participan complejos fenómenos que van desde la creación de una estructura de marcos que confluye con las identidades individual y colectiva de los actores a la redefinición de las diferentes variables que se dan en la acción hasta su definitiva resolución. Sin duda estos procesos pueden y deben ser insertados en un proceso de larga duración, y no es posible que puedan ser comprendidos en toda su integridad prescindiendo de los aspectos simbólicos, culturales, antropológicos e incluso éticos que los caracterizan. Pero mucho menos si se descontextualizan de las coordenadas sociohistóricas concretas en que tienen lugar y se aíslan de otros fenómenos simultáneos que discurren unas veces de forma paralela, otras tangente y otras secante a dichas acciones. Que 134 de los 386 varones implicados en ocupaciones de bienes de la Iglesia también se viesen involucrados en actos de violencia política o protesta social sin ninguna relación con acciones colectivas de naturaleza anticlerical; que 64 de ellos participasen en la resistencia al golpe de Estado y 104 fuesen encartados por la jurisdicción de guerra o detenidos gubernativamente tras la sublevación resulta bien expresivo de esas complejas relaciones a las que aludimos y de la imposibilidad de establecer nítidas líneas divisorias entre lo religioso, lo politico y lo social.

Los dirigentes societarios podían abominar a sus párrocos debido a su real, presunta o imaginada voluptuosidad sexual, sus mayores facilidades de acceso a las mujeres o la 
"competencia» que suponían a la hora de influir en sus almas, en sus mentes y en sus corazones. Podían, en algún caso, mostrarse resentidos por haber tenido que acudir a alguna institución de caridad regentada por clérigos, por haber recibido cualquier clase de instrucción o por haber soportado sus enseñanzas acompañadas con todas las connotaciones que conllevaba verse obligados a recurrir a esa clase de servicios. Podían, incluso, haber sido socializados en la omnipresencia de la Iglesia en el espacio público y en unas prácticas religiosas opresivas y agobiantes que marcaban su existencia cotidiana desde el nacimiento a la muerte y contra las que se sentían en la necesidad de rebelarse o podían estar convencidos de que desenmascarando a los malos pastores no hacían sino cumplir con la más sagrada de las máximas de la moral cristiana tradicional. Podían, estimulados por el esfuerzo sin precedentes de movilización política desarrollado por la Iglesia a partir de 1932, representársela como el aliado tradicional de las clases dominantes al que había que domeñar. Pero, a nuestro juicio, el determinante último en la transformación de la conciencia colectiva que conduce a que el conflicto anticlerical se exprese en forma de una acción colectiva de protesta más o menos violenta es de naturaleza fundamentalmente política o, si se quiere, sociopolítica.

La nueva estructura de oportunidades resultante del triunfo de las izquierdas en febrero de 1936 altera de forma sustancial las coordenadas en las que se desenvuelven los actores y brinda un potencial estructural objetivo para la acción sobre el que pueden operar las estrategias de alineamiento de marcos. No es nada probable que quien carece en absoluto de recursos adopte una estrategia de rebelión que puede conducir a su liquidación, como tampoco lo harán los que perciban que una valoración global coste/beneficio no resulta favorable a sus intereses. La explosión societaria que conoce buena parte del rural galaico multiplica los complejos organizacionales donde actúan nuevos y viejos apóstoles de la acción redefiniendo reivindicaciones, estrategias y objetivos en el marco de una estructura de redes preexistente y en continua efervescencia. En su interior tanto o más importantes son los incentivos relacionados con los intereses inmediatos y cotidianos de los vecinos como los de naturaleza política o social, a los que siempre son más sensibles los líderes. Sobre el nivel micro de la parroquia o el más amplio de la comarca en el que se crean esas redes no visibles en las que se generan los sentimientos de solidaridad e identidad colectiva, y en el que continúa desenvolviéndose mayoritariamente la protesta, actúan cada vez más factores exógenos, que testimonian los perceptibles avances hacia su mayor dimensionamiento e integración. Y todo ello estimulado por la auténtica revolución que supone el cambio en el poder municipal que trae consigo, ahora sí, el desplazamiento, cuando menos parcial, de una parte significativa de las elites tradicionales y que invita a repensar y a profundizar en esa aparente incapacidad gubernamental para poner coto a la violencia a la que se refería J. de la Cueva (1998: 259). 
Sólo de este modo puede explicarse la activación de la protesta coincidiendo con fechas o acontecimientos de indudable significación política, como los primeros asaltos a templos y rectorales tras conocerse los resultados de las elecciones de febrero, los que tienen lugar en el contexto de las celebraciones del aniversario de la República o del 1 de mayo o tras los asesinatos de cuatro obreros comunistas los días 6 y 8 de junio. Pero también aprovechando fechas muy simbólicas como el carnaval, el inicio de la Cuaresma o durante la celebración de la Semana Santa.Y sólo de este modo puede entenderse cómo las manifestaciones anticlericales que nos ocupan adquieren un significado político explícito como parte de una estrategia en la que siempre estuvo presente la aspiración de construir un nuevo modelo de sociedad, un nuevo «paraíso» que cada cual entendía a su modo.

\section{AGRADECIMIENTOS}

Agradezco los comentarios y sugerencias recibidas por parte de los revisores de Historia Agraria que evaluaron este artículo.

\section{REFERENCIAS}

ALBERTí, J. (2008). La Iglesia en llamas: La persecución religiosa en España durante la guerra civil. Barcelona: Destino.

AlcalÁ, C. (2001). Persecución en la retaguardia: Cataluña, 1936-1939. Madrid: Actas.

Álvarez, S. (1985). Memorias. I: Recuerdos de infancia y de juventud (1920-1936). A Coruña: Ediciós do Castro.

ÁlvAREZ, S. (1989). Las milicias populares gallegas: Un símbolo de la Galicia antifranquista: Ensayo histórico. A Coruña: Ediciós do Castro.

Álvarez JunCo, J. (1985). El anticlericalismo en el movimiento obrero. En VV. AA., Octubre 1934: Cincuenta años para la reflexión (pp. 283-300). Madrid: Siglo XXI.

Álvarez TARdío, M. \& Villa, R. (2013). El impacto de la violencia anticlerical en la primavera de 1936 y la respuesta de las autoridades. Historia Sacra, 65 (132), 683-764.

Aston, M. (1988). England's Iconoclasts:Volume 1: Law against Images. Oxford: Clarendon Press.

BARRIOS, J. M. (2007). Iconoclastia (1930-1936): La ciudad de Dios frente a la modernidad. Granada: Universidad de Granada.

Callahan, W. J. (1989). Iglesia, poder y sociedad en España, 1750-1874. Madrid: Nerea.

CÁrCel OrTí, V. (1990). La persecución religiosa en España durante la Segunda República (1931-1939). Madrid: Rialp. 
CárCel OrTí, V. (1995). Mártires españoles del siglo XX. Madrid: Biblioteca de Autores Cristianos.

CÁRCEL ORTí, V. (1999). Buio sull'altare (1931-1939): La persecuzione della Chiesa in Spagna. Roma: Città Nuova.

CÁrCEL ORTí, V. (2000). La gran persecución: España, 1931-1939. Barcelona: Planeta.

CÁRCEL ORTí, V. (2008). Caídos, víctimas y mártires: La Iglesia y la hecatombe de 1936. Madrid: Espasa Calpe.

CARo BAROJA, J. (1980). Introducción a una historia contemporánea del anticlericalismo español. Madrid: Istmo.

CASTRO, D. (1997). Cultura, política y cultura política en la violencia anticlerical. En R. Cruz \& M. PÉrez Ledesma (Eds.), Cultura y movilización en la España contemporánea (pp. 69-97). Madrid: Alianza.

Chadwich, O. (1990). The Rise of Anticlericalism. En The Secularization of the European Mind in the Nineteenth's Century (pp. 107-139). Cambridge: Cambridge University Press.

CHRISTIAN, W. A. (1978). Religiosidad popular: Estudio antropológico en un valle español. Madrid:Tecnos.

Christian, W. A. (1997). Las visiones de Ezkioga: La Segunda República y el reino de Cristo. Barcelona: Ariel.

Cruz, R. (1997). Los estudios sobre anticlericalismo en España al final del milenio. Ayer, (27), 219-229.

CRUZ, R. (2006). En el nombre del pueblo: República, rebelión y guerra en la España de 1936. Madrid: Siglo XXI.

CuEva, J. DE LA (1997). Movilización política e identidad anticlerical, 1898-1910. Ayer, (27), 101-125.

Cueva, J. DE LA (1998). El anticlericalismo en la Segunda República y la Guerra Civil. En E. La Parra \& M. SuÁrez Cortina (Eds.), El anticlericalismo español contemporáneo (pp. 211-301). Madrid: Biblioteca Nueva.

Cueva, J. DE LA (2001). Guerra civil y violencia anticlerical en Cataluña: Un ensayo de interpretación. Madrid: Instituto Universitario Ortega y Gasset.

Delgado, M. (1989). La antirreligiosidad popular en España. En L. C. Álvarez, M. J. BuXó \& S. RODRíGuez BECERRA (Eds.), La religiosidad popular. I: Antropología e historia (pp. 499-516). Barcelona/Sevilla: Anthropos/Fundación Machado.

Delgado, M. (1993). Cultura de la violencia y violencia de la historia en Centelles, verano de 1936. Historia y Fuente Oral, (9), 103-117.

Delgado, M. (1997). Anticlericalismo, espacio y poder: La destrucción de los rituales católicos, 1931-1939. Ayer, (27), 149-180.

Delgado, M. (2001). Luces iconoclastas: Anticlericalismo, espacio y ritual en la España contemporánea. Barcelona: Ariel. 
Delgado, M. (2012 [1992]). La ira sagrada: Anticlericalismo, iconoclastia y antirritualismo en la España contemporánea. Barcelona: RBA.

DuARTE, D. (2014). Os ataques anticlericais na I República (1910-1917): Historiografia, violência e performance. En P. GodINHo (Coord.), Antropologia e Perfomance:Agir, atuar, exibir (pp. 147-170). Castro Verde: 100LUZ.

GEeRTZ, C. (1987). La religión como sistema cultural. En La interpretación de las culturas (pp. 87-117). Barcelona: Gedisa.

Gilmore, D. D. (1980). The People of the Plain: Class and Community in Lower Andalusia. New York: Columbia University Press.

González Probados, M. (1992). A acción agraria socialista na II República. En D. PeREIRA (Coord.), Os conquistadores modernos: Movemento obreiro na Galicia de anteguerra (pp. 173-194). Vigo: A Nosa Terra.

GonZÁlez Rodríguez, M. E. (Ed.) (2007). Quiénes son y de dónde vienen: 498 mártires del siglo XX en España. Madrid: EDICE.

Guijarro, J. F. (2006). Persecución religiosa y guerra civil: La Iglesia en Madrid, 19361939. Madrid: La Esfera de los Libros.

Gusfield, J. (1994). La reflexividad de los movimientos sociales: Una revisión de las teorías sobre la sociedad de masas y el comportamiento colectivo. En E. LARAÑa \& J. GUSFIELD (Coords.), Los nuevos movimientos sociales: De la ideología a la identidad (pp. 93-117). Madrid: Centro de Investigaciones Sociológicas.

Hernández Figueiredo, J. R. (2009). Destrucción del patrimonio religioso en la II República (1931-1936) a la luz de los informes inéditos del Archivo SecretoVaticano. Madrid: Biblioteca de Autores Cristianos.

HunT, S., BENFORD, R. \& SNOw, D. (1994). Marcos de acción colectiva y campos de identidad en la construcción social de los movimientos. En E. LARAÑa \& J. GUSFIELD (Coords.), Los nuevos movimientos sociales: De la ideología a la identidad (pp. 221-249). Madrid: Centro de Investigaciones Sociológicas.

Jimeno, J. \& JimÉnez Gómez, F. M. (2004). El cayado roto: Narciso de Estenaga, Obispo de Ciudad Real:Testimonio de un pastor en tiempos de violencia. Madrid: Biblioteca de Autores Cristianos.

KLANDERMANS, B. (1994). La construcción social de la protesta y los campos pluriorganizativos. En E. LARAÑa \& J. GUSFIELD (Coords.), Los nuevos movimientos sociales: De la ideología a la identidad (pp. 183-219). Madrid: Centro de Investigaciones Sociológicas.

Ledesma, J. L. (2009). Delenda est Ecclesia: De la violencia anticlerical y la Guerra Civil de 1936. Working Paper. Seminario de Historia, Instituto Universitario Ortega y Gasset. Madrid, 25 de junio de 2009. http://pendientedemigracion.ucm.es/info/ historia/ortega/4-09.pdf 
Lincoln, B. (1981). Priests, Warriors, and Cattle: A Study in the Ecology of Religions. Berkeley: University of California Press.

LinColn, B. (1985). Revolutionary Exhumations in Spain, July 1936. Comparative Studies in Society and History, 27 (2), 241-260.

López Villaverde, A. L. (2008). El gorro frigio y la mitra frente a frente: Construcción y diversidad territorial del conflicto político-religioso en la España republicana. Barcelona: Rubeo.

MARTín Rubio, A. D. (1999). Salvar la memoria: Una reflexión sobre las víctimas de la guerra civil. Badajoz: Fondo de Estudios Sociales.

MARTín RUBIO, A. D. (2001). La persecución religiosa en España (1931-1939): Una aportación sobre las cifras. Hispania Sacra, 53 (107), 63-89.

Martín Rubio, A. D. (2007). La cruz, el perdón y la gloria: La persecución religiosa en España durante la II República y la guerra civil. Madrid: Ciudadela Libros.

MARTínez Puche, J. A. (2007). Mártires dominicos españoles: 1936: 92 religiosos, religiosas y seglares de la familia dominicana martirizados en la persecución religiosa de 1936. Madrid: Edibesa.

Mitchell, T. J. (1988). Violence and Piety in Spanish Folklore. Philadelphia: University of Pennsylvania Press.

Montero, A. (1998 [1961]). Historia de la persecución religiosa en España, 1936-1939. Madrid: Biblioteca de Autores Cristianos.

Moral, A. M. (2012). Anticlericalismo y poder: La desacralización de las calles y los espacios públicos durante la Segunda República. Hispania Sacra, 64 (Extra 1), 47-68.

NúÑEz LóPEZ, J. (2010). Síntesis de la persecución religiosa en España del año 1934 al 1939. Vigo: Cardeñoso.

Opp, K. D. (2009). Theories of Political Protest and Social Movements: A Multidisciplinary Introduction, Critique, and Synthesis. London: Routledge.

PeraIRE, J. (2001). Cantando hacia la muerte: Heroico testimonio martirial del joven Francisco Castelló Aleu. Madrid: Biblioteca de Autores Cristianos.

PÉrez Arnal, M. (2010). Encargos espirituales y reflexiones: Escritos del siervo de Dios durante la persecución religiosa de 1936-1939. Valencia: Editorial Cultural y Espiritual Popular.

Pérez Ledesma, M. (1999). «Viva la libertad, mueran los frailes!»: El anticlericalismo en la España contemporánea. Revista de Libros, (30). http://www.revistadelibros.com/ articulos/viva-la-libertad-mueran-los-frailes-el-anticlericalismo-en-la-espana-contemporanea

Pons, G. (2000). Bebieron el cáliz del Señor: Sacerdotes de Menorca inmolados por la fe (1936). Madrid: Biblioteca de Autores Cristianos.

PRADA, J. (2006). De la agitación republicana a la represión franquista: (Ourense 19341939). Barcelona: Ariel. 
RANZATO, G. (1988). Dies irae: La persecuzione religiosa nella zona republicana durante la Guerra Civile spagnola (1936-1939). Movimento operaio e socialista, (2), 195-220.

RAGUER, H. (1989). "Dies irae" di Gabrielle Ranzato: "Ira di Dio", ma rabbia di chi? Movimento operaio e socialista, (3), 155-171.

REY, F. DEL (2008). Paisanos en lucha: Exclusión política y violencia en la Segunda República española. Madrid: Biblioteca Nueva.

RudÉ, G. (2009 [1971]). La multitud en la Historia: Los disturbios populares en Francia e Inglaterra, 1730-1848. Madrid: Siglo XXI.

SouTo, M. J. (1997). La represión franquista en la provincia de Lugo (1936-1940). Tesis de doctorado. Santiago de Compostela: Universidade de Santiago de Compostela.

Thomas, M. (2014). La fe y la furia:Violencia anticlerical popular e iconoclasta en España, 1931-1936. Granada: Comares.

VinCENT, M. (2005). "The Keys of the Kingdom": Religious Violence in the Spanish Civil War, July-August 1936. En C. EALHAM \& M. Richards (Eds.), The Splintering of Spain: Cultural History and the Spanish CivilWar, 1936-1939 (pp. 68-89). Cambridge: Cambridge University Press. 